\title{
Knowledge, Attitude and Practice regarding Cervical Cancer Screening Amongst Women visiting Tertiary Centre in Kathmandu, Nepal
}

\author{
Shrestha $S,{ }^{* *}$ Saha $R,{ }^{2}$ Tripathi $N^{3}$ \\ ${ }^{1}$ Department of Obstetrics and Gynaecology, Manipal College of Medical Sciences Pokhara, Nepal, ${ }^{2}$ Department of \\ Obstetrics and Gynaecology, Kathmandu Medical College, Sinamangal, Kathmandu, Nepal, ${ }^{3}$ Medical Officer, Gandaki \\ Medical College and Teaching Hospital, Pokhara, Nepal
}

* Corresponding Author:

Dr Junu Shrestha

Manipal Teaching Hospital

Phulbari, Pokhara - 33701, Nepal

E mail : junu152001@yahoo.com

\section{Citation}

Shrestha J, Saha R, Tripathi N. Knowledge, Attitude and Practice regarding Cervical Cancer Screening Amongst Women visiting Tertiary Centre in Kathmandu, Nepal. Nepal Journal of Medical sciences 2013;2(2):85-90.

\section{Background:}

Cervical cancer is the second most common cancer in women worldwide. It is the most common cancer in the developing and underdeveloped countries which bear more than $80 \%$ of the global burden of the disease. ${ }^{1}$ It is estimated that every year, 500,000 women develop cervical cancer and almost 274,000 of them die from the disease. ${ }^{2}$ South-east Asian

\begin{abstract}
Background: Cervical cancer is one of the commonest cancers in Nepal. Fortunately, it is preventable by detecting precancerous lesions and early invasive cancers by various screening tools. Screening can be possible if women are aware of the problem and if they have positive attitude. Therefore this study was conducted to find out about the knowledge, attitude and practice of cervical cancer in Nepalese women attending a tertiary level hospital in Nepal.
\end{abstract}

Methods: A cross-sectional questionnaire based study was conducted in gynaecological out patient department of Kathmandu Medical College from January to March 2011. Structured questionnaire was used. Demographic profile of women was noted and questions pertaining to knowledge, attitude and practice on screening for cervical cancer were asked.

Results: There were 105 respondents, of whom $65.7 \%$ had heard about cervical cancer. However, only $42.9 \%$ and $18.1 \%$ had knowledge about screening for cervical cancer and Pap smear test respectively. More than $85 \%$ of women had positive attitude towards screening but the uptake of Pap smear test in the respondents was only $10.5 \%$. It was found that advancing age and longer duration of marriage were significantly associated with better knowledge, attitude and practice.

Conclusion: Knowledge and practice of the screening for cervical cancer was poor in gynaecological patients visiting a tertiary level hospital. However the attitude of women towards screening was positive.

Keywords: Attitudes, cancer screening tests, health knowledge, practice, uterine cervical neoplasm

countries like India, Nepal and Srilanka jointly contribute to nearly one-third of the global cervical cancer burden. ${ }^{3}$

The key to reducing cervical cancer morbidity and mortality is early detection and treatment of cervical precancerous lesions as fortunately, it is one of the most preventable cancers. ${ }^{4}$ It is known that precancerous lesions are detectable ten years prior to the advancement to cancer. Therefore, de- 
tecting and treating women during this period using various screening tools helps in reducing the incidence of cervical cancer and the mortality related to it. ${ }^{5-7}$ It has been claimed that majority of cervical cancer could be prevented if women were offered and complied with cytological screening programmes. ${ }^{8}$ Recently, prophylactic vaccines to human papilloma virus also have claimed the potential of protecting the girls of new generation.

Although cervical cancer is more common in the developing countries compared to the developed countries, it has been estimated that only $5 \%$ of women of developing countries are screened by Pap smear compared to 40 to $50 \%$ in the developed countries. ${ }^{9}$ Screening is underutilized in the developing countries due to a number of factors like poor educational background, lack of knowledge regarding the availability and benefits of screening, lack of information from part of health care workers, affordability of screening tools by the individual, cultural barriers, unavailability of facilities at all health centres and the like. Of these, lack of awareness and attitude, wrong beliefs about the disease and screening for it are one of the major factors.

Nepal is a country carrying a huge burden of cervical cancer and unfortunately there is no national cancer screening programme for cervical cancer. The success and benefit screening at a national level as a public health program to control and prevent cervical cancer depends to a great extent on the level of awareness of the potential beneficiaries. There has not been any previous study to assess the knowledge, attitude and practice of cervical cancer screening in Nepalese women. Therefore, this study is conducted with the aim to gather information regarding the knowledge, attitude and practice of cervical cancer screening in relation to demographic profile in Nepalese women attending a tertiary level hospital in Nepal.

\section{Methods:}

This is a cross sectional study conducted at the Gynaecology Out Patient Department of Kathmandu Medical College teaching hospital, a tertiary level referral hospital in Kathmandu with daily out patient load of 100 to 120 patients. The study was conducted from January 2011 to March 2011 for a period of three months. Participants were the patients visiting the researcher for various other gynaecological problems in the OPD on Tuesdays and Fridays of the study period. All the women who gave informed consent to participate in the study were included while those failing to give consent were excluded. Women coming for obstetric checkups in the OPD were also excluded. Face to face interview was held with the patients by the researcher herself using preformed questionnaire.

Structured questionnaire was prepared with various questions regarding the socio-demographic profile of patients and questions to assess the knowledge, attitude and practice of cervical cancer screening. Socio-demographic characteristics included age of patients, address and educational status, marital status, duration of marriage and parity. In order to assess the knowledge of patients questions like if they had any idea about cervical cancer, about screening for cervical cancer, if they have heard about pap smear test or any other tests used for screening, how frequently they should be screened, if they had knowledge, how they had acquired the knowledge, were asked. Their attitude was evaluated by asking them if they thought it was necessary to screen every woman who was sexually active. In order to review the practice of screening they were asked if they had undergone any screening test like pap smear test, if they have how many times they had undergone such test and if they have not undergone such test, what was the reason behind it.

In order to evaluate the level of their knowledge, attitude and practice, Knowledge, Attitude and Practice (KAP) score was also calculated. There were four questions in the questionnaire which determined the level of knowledge of patients, " have you heard about cancer cervix? have you heard about screening for cancer cervix? have you heard about pap smear test? and have you heard about other screening test for pap smear test?". Likewise, attitude determining question was " do you think all women who are sexually active need to be screened for cancer cervix?". in order to see their practice status, they were asked if they had ever been screened for cancer cervix. For these six questions pertaining to knowledge, attitude and practice, score 1 was given for positive answer and score 0 was given for negative answer. Total of scores for all six answers made the cumulative KAP score.

The data collected were entered in the excel chart sheet. Analysis was done using simple percentage. Further analysis of the KAP score was done in comparison with different demographic characteristics using Epi Info version (3.4.1). In order to establish the statistical significance, data on the KA P score were compared by applying chi-square test. P value less than 0.05 was considered statistically significant.

\section{Results:}

There were total of 105 participants. The socio-demographic profiles of these participants are presented in table 1 . 
Original Article | Shrestha J, et al. Knowledge, Attitude and Practice of cervical cancer screening

Table 1: Socio-demographic Profile of the Participants

\begin{tabular}{|c|c|}
\hline Socio-demographic Profile Age & Number \\
\hline$<20$ years & $7(6.7 \%)$ \\
\hline 20-29 years & $49(46.7 \%)$ \\
\hline $30-39$ years & $35(33.3 \%)$ \\
\hline 40-49 years & $12(11.4 \%)$ \\
\hline $50-59$ years & $21.9 \%)$ \\
\hline$>60$ years & $0(0 \% 0$ \\
\hline Total & $105(100 \%)$ \\
\hline \multicolumn{2}{|l|}{ Address } \\
\hline Urban & $88(83.8 \%)$ \\
\hline Rural & $17(16.2 \%)$ \\
\hline Total & $105(100 \%)$ \\
\hline \multicolumn{2}{|l|}{ Educational Status } \\
\hline Illiterate & $20(19 \%)$ \\
\hline Primary & $10(9.52 \%)$ \\
\hline Secondary & $39(37.1 \%)$ \\
\hline Higher Secondary & $19(18.1 \%)$ \\
\hline University & $17(16.2 \%)$ \\
\hline Total & $105(100 \%)$ \\
\hline \multicolumn{2}{|l|}{ Marital Status } \\
\hline Unmarried & $7(6.7 \%)$ \\
\hline Married & $96(91.4 \%)$ \\
\hline Separated & $1(0.95 \%)$ \\
\hline Widowed & $1(0.95 \%)$ \\
\hline Total & $105(100 \%)$ \\
\hline \multicolumn{2}{|l|}{ Duration of Marriage } \\
\hline Unmarried & $7(6.7 \%)$ \\
\hline $1-10$ years & $52(49.5 \%)$ \\
\hline $11-20$ years & $34(32.4 \%)$ \\
\hline$>20$ years & $12(11.4 \%)$ \\
\hline Total & $105(100 \%)$ \\
\hline \multicolumn{2}{|l|}{ Parity } \\
\hline 0 & $27(25.7 \%)$ \\
\hline 1 & $29(27.6 \%)$ \\
\hline 2 & $27(25.7 \%)$ \\
\hline 3 & $14(13.3 \%)$ \\
\hline$\geq 4$ & $8(7.6 \%)$ \\
\hline Total & $105(100 \%)$ \\
\hline
\end{tabular}

The mean age of the respondents was 29.9 years. Most of them were from urban areas $(83.8 \%)$ and majority had secondary $(37.1 \%)$ and higher secondary level (18.1\%) of education. More than $90 \%$ were married. The mean age at marriage was 19.6 years and the mean duration of marriage was 11.1 years. The mean parity was 1.6. Knowledge, attitude and practice of women towards cervical cancer screening are presented in table 2 .

Table 2: Knowledge, attitude and practice of women towards cervical cancer screening

\begin{tabular}{lcc}
\hline \multicolumn{1}{c}{$\begin{array}{c}\text { KAP Response of } \\
\text { Women }\end{array}$} & $\begin{array}{c}\text { Number of } \\
\text { women }\end{array}$ & Percentage \\
\hline Have you heard about cervical cancer? & \\
Yes & 69 & 65.7 \\
No & 36 & 34.3 \\
Have you heard about screening for cervical cancer? \\
Yes & 45 & 42.9 \\
No & 60 & 57.1 \\
Have you about Pap test? & & \\
Yes & 19 & 18.1 \\
No & 86 & 81.9
\end{tabular}

Have you heard about other tests for screening for cervical cancer?

$\begin{array}{lcc}\text { Yes } & 3 & 2.9 \\ \text { No } & 102 & 97.1\end{array}$

Where did you hear about the pap test?*

$\begin{array}{lcc}\text { Health professionals } & 15 & 14.3 \\ \text { Media } & 8 & 7.6 \\ \text { Friends and relatives } & 19 & 18.1 \\ \text { Books/Newpapers } & 2 & 1.9\end{array}$

How often do you think do you need to do Pap test?

$\begin{array}{lcc}\text { No idea } & 44 & 41.9 \\ 3 \text { monthly } & 18 & 17.1 \\ 6 \text { monthly } & 19 & 18.1 \\ 1 \text { yearly } & 23 & 21.9 \\ 3 \text { yearly } & 1 & 0.95\end{array}$

Do you think all women above 30 years need to be screened for cervical cancer?

$\begin{array}{lll}\text { Yes } & 90 & 85.7\end{array}$

$\begin{array}{lll}\text { No } & 15 & 14.3\end{array}$

Have you been screened for cervical cancer?

$\begin{array}{lll}\text { Yes } & 11 & 10.5\end{array}$

No $\quad 94 \quad 89.5$

How many times have you been screened? **

Once $\quad 6 \quad 54.5$

$\begin{array}{lll}\text { Twice } & 4 & 36.4\end{array}$

Thrice $\quad 1 \quad 9.1$

If you have not been screened, why not?***

$\begin{array}{lll}\text { No knowledge } & 30 & 31.9\end{array}$

No symptoms $\quad 50 \quad 53.2$

$\begin{array}{lll}\text { Not advised } & 2 & 2.1\end{array}$

No time $\quad 5 \quad 5.3$

No money $\quad 1 \quad 1.1$

Embarrassment $\quad 2 \quad 2.1$

No need 44.3

* More than one response possible.

** Total is women who had undergone screening (11).

*** Total is women who had not undergone screening (94).

Though $65 \%$ of women have heard about cervical cancer, only $42.9 \%$ have heard about its screening. Ironically, only 
18\% knew and had heard about Pap smear test. Very few $(2.9 \%)$ had heard about other tests for screening. More than $85 \%$ respondents had positive attitude towards screening and only $10.5 \%$ women had at least been screened once for cervical cancer during their lifetime.

The KAP score of the women in relation to the different demographic profile is presented in Table No 3.

Table No 3: Knowledge, Attitude and Practice (KAP) Score of the patients in relation to Demographic Profile.

\begin{tabular}{|c|c|c|c|c|}
\hline $\begin{array}{c}\text { Socio-demographic } \\
\text { Profile }\end{array}$ & No. & $\%$ & $\begin{array}{c}\text { Mean } \\
\text { KAP score }\end{array}$ & P value \\
\hline \multicolumn{5}{|l|}{ Age } \\
\hline$<20$ years & 7 & 6.7 & 1.71 & \multirow{7}{*}{0.013} \\
\hline 20-29 years & 49 & 46.7 & 1.78 & \\
\hline $30-39$ years & 35 & 33.3 & 2.40 & \\
\hline 40-49 years & 12 & 11.4 & 3.33 & \\
\hline $50-59$ years & 2 & 1.9 & 4.00 & \\
\hline$>60$ years & 0 & 0 & 0.00 & \\
\hline Total & 105 & 100 & & \\
\hline \multicolumn{5}{|l|}{ Address } \\
\hline Urban & 88 & 83.8 & 2.27 & \multirow{3}{*}{0.089} \\
\hline Rural & 17 & 16.2 & 1.82 & \\
\hline Total & 105 & 100 & & \\
\hline \multicolumn{5}{|l|}{ Educational Status } \\
\hline Illiterate & 20 & 19 & 1.50 & \multirow{6}{*}{0.081} \\
\hline Primary & 10 & 9.52 & 3.30 & \\
\hline Secondary & 39 & 37.1 & 2.21 & \\
\hline Higher Secondary & 19 & 18.1 & 2.26 & \\
\hline University & 17 & 16.2 & 2.29 & \\
\hline Total & 105 & 100 & & \\
\hline \multicolumn{5}{|l|}{ Marital Status } \\
\hline Unmarried & 7 & 6.7 & 1.86 & \multirow{5}{*}{0.262} \\
\hline Married & 96 & 91.4 & 2.19 & \\
\hline Separated & 1 & 0.95 & 4.00 & \\
\hline Widowed & 1 & 0.95 & 4.00 & \\
\hline Total & 105 & 100 & & \\
\hline \multicolumn{5}{|c|}{ Duration of Marriage } \\
\hline Unmarried & 7 & 6.7 & 1.86 & \multirow{5}{*}{0.003} \\
\hline $1-10$ years & 52 & 49.5 & 1.83 & \\
\hline $11-20$ years & 34 & 32.4 & 2.56 & \\
\hline$>20$ years & 12 & 11.4 & 3.08 & \\
\hline Total & 105 & 100 & & \\
\hline \multicolumn{5}{|l|}{ Parity } \\
\hline 0 & 27 & 25.7 & 1.74 & \multirow{6}{*}{0.153} \\
\hline 1 & 29 & 27.6 & 1.93 & \\
\hline 2 & 27 & 25.7 & 2.74 & \\
\hline 3 & 14 & 13.3 & 2.21 & \\
\hline$\geq 4$ & 8 & 7.6 & 2.88 & \\
\hline Total & 105 & 100 & & \\
\hline
\end{tabular}

The KAP score was the highest in the women of 40-59 years of age. Likewise, KAP score was more in respondents from urban areas. KAP score was comparatively higher in women with primary level of education and in those who had been married for more than 20 years.

\section{Discussion:}

Despite being one of the common cancers in women in Nepal, there is no systematic national programme for cervical cancer screening in Nepal. Various screening tools like Pap smear test, visual inspection with Acetic acid and Lugol's iodine are used for screening to detect precancerous lesions and early invasive cancers. However, success of any screening test depends on being properly utilized by the target population. The uptake of screening on the other hand is dependent on health care system and its professionals and on the women themselves. The present study is focused in determining the knowledge, attitude and practice of the women, which is one of the major factors that determine the success of any screening programme.

In our study, $65.7 \%$ of women had heard about cervical cancer. This was similar to that reported by other study conducted in South Eastern Nigeria and in Korea ${ }^{10,11}$ but was lesser than that reported by another study from Qatar. ${ }^{12}$ A study in India reported only $16 \%$ of women having heard about cervical cancer. ${ }^{13}$ The fact that this study was conducted in a tertiary centre in capital of Nepal where women are at better access to acquiring the information, could be the reason for large proportion of women having heard about cervical cancer. Also, more than $70 \%$ respondents in this study have secondary or higher level of education.

It was seen that $42 \%$ of the respondents have knowledge that cervical cancer could be screened and that it is a preventable disease. Nevertheless, when asked about Pap smear, only $18 \%$ knew about it. This was better than the awareness about screening reported in African countries. ${ }^{14,15}$ Another study conducted in India also reported poorer knowledge about Pap smear compared to our respondents. ${ }^{13}$ However, level of knowledge is better in developed countries. ${ }^{12,16}$

When asked only 3 respondents said they had heard about other tests for screening and all three responded it to be cervical biopsy. Only one respondent had the correct idea about how frequently they should go about screening. Others opined that they thought they should be screened from 3 months to one year. Another study quoted 39\% of the respondents having correct knowledge about screening interval which is much higher than in our study ${ }^{17}$; the reason is that in this study, respondents were the medical workers 
with better knowledge than that of general population.

Most of the people who had heard about the Pap smear test stated that they got the information from friends and relatives $(18 \%)$ followed by health professions (14.3\%) and media $(7.6 \%)$. This is similar to that found in another study where friends and relatives followed by gynaecologist was the source of their knowledge. ${ }^{12}$ Another study asserted health personnel to be the source of knowledge in most of the respondents. ${ }^{16}$

To our question to whether all women who are sexually active be screened for cervical cancer, majority of the respondents $(85.7 \%)$ responded positively as reported in other studies. ${ }^{12,16}$ Only $14.3 \%$ said that it was not necessary. This was better than that stated in a study where, only $57.1 \%$ showed positive attitude to undergo the test. ${ }^{14}$ Usually the Nepalese women are open minded and are open to any screening test they are offered. This is an advantage that would help in making any screening programme successful.

Uptake of Pap smear test was only $10.5 \%$ in our respondents, similar to that reported by Roy B et al in India. ${ }^{13}$ In Nigeria still lower uptake of Pap smear test was reported ${ }^{14}$ and more so even in a study done in female health workers, only $14.6 \%$ of these health workers had undergone of Pap smear test. ${ }^{18}$ Utilization of Pap smear test on the other hand was better in women in Qatar and Kuwait. ${ }^{12,16}$ Lack of advocacy for screening and lack of screening programme at the national level is the reason behind the low uptake of Pap smear in Nepal.

On being asked on why they had not undergone screening, majority responded they had no symptoms (53.2\%). About 32\% stated lack of knowledge to be the reason for not undergoing screening procedure. Other reasons were not being advised, not felt need, no time and no money. However, almost $50 \%$ of respondents in another study stated their reason for not taking the test to be not being advised by the doctor. Other reasons were fear of pain, embarrassment, no symptoms, etc. ${ }^{16}$ Lack of knowledge was the main reason for not utilizing the test in a study done in tertiary centre in Nigeria. ${ }^{14}$ Therefore, imparting knowledge by various awareness campaigns and also by the health personnel during their visits to health centre for any other reasons would improve uptake of the screening tests.

On analyzing the knowledge, attitude and practice (KAP) score of the respondents with the demographic profile, only age and duration of marriage were found to be significant with the better KAP scores. Women between 50 to 59 years had the best KAP score followed by those between 40 to 49 years and this was found to be statistically significant. Women less than 20 years had comparatively poorer knowledge, attitude and practice. Likewise, longer duration of marriage, i.e., when duration was more than 20 years, women had better KAP score. However, knowledge was better in women aged 30 to 49 years of age in other studies. ${ }^{12,16}$ Similar results of better knowledge score with respect to longer duration of marriage was reported in another study as well. ${ }^{12}$ More advanced age and longer duration of marriage would probably expose the women more to the health centres for various other reasons. So, probably they would be more aware about their own health status and hence their level of knowledge, attitude and practice. This could be reason why the KAP score was found to be more who had higher parity index, though the results are not statistically significant. Similar was the results of the study conducted by Al Meer et al in Qatar. ${ }^{12}$

Women living in urban area had better KAP score compared to those from rural areas in this study, the reasons being in urban area, women had better access to media and health care services, thus improving the women's knowledge, attitude and practice. Respondents with primary level of education had better KAP scores compared to those with secondary and higher level of education, contrary to our belief that with better educational status the KAP score would improve as shown in other studies. ${ }^{12,14}$ In the present study the number of women having primary level of education was very less , 9.5\% compared to those with secondary and higher level of education. Larger population in these sub groups had KAP scores at extremes of points making the mean less. However, the difference as per the educational level was not found to be statistically significant. Women who were separated and divorced had better KAP scores than married women in our study. Similar results with better knowledge scores in divorced women was shown in another study. ${ }^{12}$ Contrarily, better knowledge score was found in married women in another study. ${ }^{16}$

\section{Conclusion:}

Knowledge and practice of the screening for cervical cancer was poor in gynaecological patients visiting a tertiary level hospital. However the attitude of women to undergo the screening test was very positive. This may limit the utilization of the screening programmes for cervical cancer. These findings suggest a need to increase intensive cervical cancer awareness campaigns on screening for cervical cancer and developing screening programmes preferably at national level. 


\section{Acknowledgements:}

We are thankful to all the faculty members and staffs of department of Obstetrics \& Gynaecology of the KMCTH for their help and support to complete this study.

\section{Conflict of interest: nil}

Funding: none

\section{References:}

1. World Health Organization (WHO) (2010). Human papillomavirus infection and cervical cancer. Available at: www.who.int/vaccine research/diseases/hpv.

2. World Health Organization (WHO), PATH, and the United Nations population fund (2009). Cervical cancer, human papillomavirus (HPV), and HPV vaccines: Key points for policymakers and health professionals. Geneva, CH: WHO; 2007. Report No : WHO/RHR/08.14 Available at: www.who.int/reproductive health/ publications/cervical_cancer_keypoints/cerv_cancer_hpv

3. Ferlay J, Shin HR, Bray F, et al (2010). Cancer incidence and mortality worldwide. GLOBOCAN 2008: IARC cancer Base No.10 [Internet]. Lyon, France: International agency for research on cancer. Available from: http://globocon.iarc.fr

4. Pontin J, Adami HO, Bergstrom R, et al. Strategies for global control of cervical cancer. Int $\mathrm{J}$ Cancer 1995;60:1-26.

5. Bergstrom R, Sparen P, Adami HO. Trends in cancer of the cervix uteri in Sweden following cytological screening. Br J Cancer 1999;81:159-66.

6. Mahlck CG, Jonsson H, Lenner P. Pap smear screening and changes in cervical cancer mortality in Sweden. Int J of Gynaecol and Obstet 1994;44: 267-72.

7. Morris M, Tortollero LG, Malpica A, et al. Cervical intraepithelial neoplasia and cervical cancer. Obstet Gynaecol Clin North Am 1996;23:347-410.

8. Healthy People 2000: national health promotion and disease prevention objectives. Washington DC, Department of Health and Human Services, United States Government Printing office, 1990.

9. Musmar SG. Pattern and factors affecting Pap smear test in Nablus, a retrospective study. Middle East Journal of Family Medicine 2004, 4(4).

10. Akujobi CN, Ikechebelu JI, Onunkwo I, et al. Knowl- edge, attitude and practice of screening for cervical cancer among female students of a tertiary institute in South Eastern Nigeria. Niger J Clin Pract 2008;11:2169.

11. Nguyen TT, Song IC, Taylor R, et al. Knowledge, Attitude and Practice (KAP) Concerning Cervical Cancer and Screening among Rural and Urban Women in Six Provinces of the Democratic People's Republic of Korea. Asian Pacific J Cancer Prev 2011;12:3029-33.

12. Al Meer FM, Aseel MT, Al Khalaf J, et al. Knowledge, attitude and practices regarding cervical cancer and screening among women visiting primary health care in Qatar. Eastern Mediterranean health Journal 2011;17:855-61.

13. Roy B, Tang TS. Cervical cancer screening in Kolkata, India: beliefs and predictors of cervical cancer screening among women attending a women's health clinic in Kolkata, India. J Cancer Educ 2008;23:253-9.

14. Mbamara SU, Ikpeze OC, Okonkwo JE, et al. Knowledge, attitude and practice of cervical cancer screening among women attending gynecology clinics in a tertiary level medical care center in southeastern Nigeria J Reprod Med 2011;56:491-6.

15. Obiechina NJ, Mbamara SU. Knowledge attitude and practice of cervical cancer screening among sexually active women in Onitsha, southeast Nigeria. Niger J Med. 2009;18:384-7.

16. Mona Al Sairafi, Farida A. Mohamed. Knowledge, attitudes and Practice related to cervical cancer screening among Kuwaiti Women. Med Princ Pract 2009;18:3542.

17. Mutyaba T, Mmiri FA, Weiderpass E. Knowledge, attitudes and practices on cervical cancer screening among the medical workers of Mulago Hospital, Uganda. BMC Med Educ 2006;6:13-6.

18. Gharoro, EP, Ikeanyi EN. An appraisal of the level of awareness and utilization of the Pap smear as a cervical cancer screening test among female health workers in a tertiary health institution. Int J Gynaecol Cancer 2006;16:1063-8. 